\title{
A comparative study of gravimetric and electrochemical techniques for the evaluation of corrosion inhibitor activity onset and efficiency in pipeline $\mathrm{CO}_{2}$ environments
}

\author{
Estudio Comparativo de técnicas electroquímicas y gravimétricas \\ para la evaluación de la actividad y eficiencia de inhibidores \\ de corrosión en ambientes con presencia de $\mathrm{CO}_{2}$
}
A. Cáceres ${ }^{1,3 *}$
M. Casales ${ }^{2}$
L. Martínez ${ }^{2}$

Recibido 21 de julio de 2017, aceptado 03 de octubre de 2018 Received: July 21, 2017 Accepted: October 03, 2018

\begin{abstract}
The monitoring of internal corrosion of pipelines is a critical element of the pipeline maintenance programs. A benchmarking study of enhanced techniques for real-time corrosion monitoring such as Linear Polarization Resistance and Harmonic Distortion Analysis was performed, enhanced Electrical Resistance in conjunction with standard metal coupon. The transition of the corrosion processes occurring in metals immersed in corrosive electrolytes at the onset of inhibitor action after its injection was found a revealing item for study. This study considered a $3 \% \mathrm{NaCl}$ solution with and without $10 \%$ diesel, saturated with $\mathrm{CO} 2$ at $50^{\circ} \mathrm{C}$ and standard AISI 1018 coupons. A set of generic corrosion imidazoline-based inhibitors was studied. The benefits of employing real-time corrosion monitoring devices include shortened test times, increased number of inhibitors evaluated, and an increase in data quality and quantity. Results show that the corrosion rates from linear polarization resistance in the solution without inhibitor were overestimated, while the Harmonic Distortion Analysis and enhanced Electrical Resistance presented similar results to Standard Coupon. The enhanced electrical resistance monitoring also proved to be a good device to reveal the onset of corrosion protection after the inhibitor is applied.
\end{abstract}

Keywords: Internal corrosion, real time corrosion monitoring, corrosion inhibitors, linear polarization resistance, harmonic analysis, electrical resistance, coupons corrosion.

\section{RESUMEN}

El monitoreo de la corrosión interna en tuberías de transporte de crudo es un elemento crítico para los programas de mantenimiento de tuberías de transporte. En este trabajo se ha desarrollado un estudio comparativo de las diferentes técnicas utilizadas en procesos de monitoreo de corrosión interior en tiempo real, tales como resistencia a la polarización lineal (LPR), análisis de distorsión de armónicos (HDA), resistencia eléctrica (ER) junto con la técnica convencional de pérdida de peso por cupones metálicos. La transición del proceso de corrosión que ocurre en un metal inmerso en un electrolito corrosivo y la respuesta de un inhibidor de corrosión una vez inyectado en el sistema corrosivo fue evaluada mediante las técnicas antes descritas. En este estudio la solución corrosiva considerada fue al 3\% de $\mathrm{NaCl}$ en presencia y ausencia de diesel, saturada con $\mathrm{CO}_{2}$ a $50{ }^{\circ} \mathrm{C}$, condiciones similares a las de transporte

\footnotetext{
1 Departamento de Ingeniería Química Metalúrgica. Facultad de Química. Universidad Nacional Autónoma de México, 04510, México, D.F., México.

2 Universidad Nacional Autónoma de México, Instituto de Ciencias Físicas, Av. Universidad S/N, Cuernavaca, Mor., México

3 Universidad ECCI, Carrera 19 No 49-20 Bogotá-Colombia.

* Autor de correspondencia: acaceresj@ecci.edu.co
} 
de crudos en la industria de transporte de crudo mexicano, el acero ensayado fue un AISI SAE 1018. Como inhibidor del proceso de corrosión por $\mathrm{CO}_{2}$, se utilizó una serie de inhibidores genéricos de tipo imidazolina. El empleo de técnicas de monitoreo en tiempo real y la rápida respuesta frente al uso de inhibidores en el medio corrosivo, mostraron la eficiencia del inhibidor utilizado y su acción inmediata fue registrada con el uso de las técnicas de monitoreo en tiempo real empleadas.

Palabras clave: Corrosión interior, monitoreo de la corrosión en tiempo real, inhibidor de corrosión, resistencia a la polarización lineal, análisis de armónicos, resistencia eléctrica, cupones de corrosión.

\section{INTRODUCTION}

In the oil and gas industry, the monitoring of internal corrosion of pipelines is considered as a top priority task. This challenge has led to the evolution of corrosion monitoring tools from passive recording coupons towards real-time monitoring, which enables pipeline operators to provide immediate response and to perform proactive measures as corrosion damage is detected [1]. Corrosion monitoring is more difficult than the monitoring of most other process parameters in the industry, since different corrosion mechanisms may coexist and there is no a single measurement technique that will detect each of them. A general range of corrosion monitoring techniques and systems has grown, particularly in the last decades, for sensing, measuring, and calculating corrosion damage. The developments of effective corrosion monitoring techniques and accessible software have allowed to take to the field new techniques providing real time and nearly instantaneous evaluation of the internal corrosion phenomena caused by the transported fluids, typically containing water and other corrosive agents $[1,2]$.

The techniques for internal corrosion monitoring usually employed are associated with electrochemical techniques such as linear polarization resistance or harmonic distortion, and metal loss measurement employing weight loss coupons and electrical resistance probes. The corrosion coupons are only capable of providing information about month to month or larger exposures [3]. On the other hand an electrochemical approach or an electrical resistance probe may provide real time corrosion diagnostic information. The goal of this study is to evaluate comparatively the following techniques: Linear Polarization Resistance (LPR), Harmonic Distortion Analysis (HDA), Electrical Resistance (ER) and weight loss coupons in corrosion system with $\mathrm{CO}_{2}$.
It is well known that weight loss coupons are used to evaluate the corrosion rates over long periods of time. This technique represents global corrosion rates in the system unlike electrochemical techniques trough which one can follow changes in the process kinetic. However, weight loss is one of the oldest techniques and widely used in industry. Monitoring techniques such as electrical resistance (ER) and Linear Polarization Resistance (LPR) can be used to provide further quick information about instantaneous corrosion in the system. The principle of the widely used ER technique is quite simple, i.e. the electrical resistance of a sensing element increases as its crosssectional area is reduced by corrosion damage, the electrical resistance technique (ER) by corrosion monitoring method grew quickly after the correlation with corrosion rates was recognized in the 1950's $[4,5]$. In the linear polarization resistance, a small potential perturbation (typically $10-20$ or even $30 \mathrm{mV}$ ) is applied to the working electrode and the resulting current is measured. The ratio of the potential to current perturbations is known as the polarization resistance that can be itself related to the corrosion current with the Stern-Geary relationship, where Tafel slopes are usually pre-established, this is $120 \mathrm{mV} / \mathrm{dec}$. Harmonic distortion is a measure of the non-linear current distortion arising during the LPR measurements. The data is analyzed with the use of Fast Fourier Transform analysis, and so obtained a measure of the corrosion current and provide an on-line estimate of Stern-Geary constant. The Stern and Geary constant is calculated front the Harmonic Analysis data, with first, second and third harmonics in the sinewave signal of frequency W [6].

\section{EXPERIMENTAL PROCEDURES}

\section{Test material and solution}

AISI 1018 carbon steel samples were employed in this study. Standard three identical electrodes with a triangular configuration were used in the 
Linear Polarization Resistance and Harmonic Distortion analysis techniques. The electrical resistance method used Microcor ${ }^{\circledR}$ probes in the cylindrical element form. Gravimetric coupons by Metal Samples® were used for the weight loss test. The surface samples were polished with 600 grit $\mathrm{SiC}$ paper and finally rinsed with distilled water, acetone and ethanol.

Experiments were performed in a $3 \mathrm{wt} \% \mathrm{NaCl}$ solution, with a $\mathrm{pH}$ value of 4.7 , in tri-distilled water and a mixture which consisted of 90 vol.\% of this solution plus 10 vol.\% diesel. The $\mathrm{CO}_{2}$ gas was bubbled during 2 hours prior to testing in order to remove the dissolved oxygen from the test solution. Through the experiment, the electrolyte was kept deareated and saturated with $\mathrm{CO}_{2}$ by continuous bubbling with $\mathrm{CO}_{2}$. For all experiments, the temperature was kept constant at $50 \pm 2{ }^{\circ} \mathrm{C}$. Inhibitor was added 2 hours after pre-corroding the specimen. The weight loss experiments lasted $336 \mathrm{~h}$ in order to follow the formation of any iron carbonate film. Additionally, the use of field measurement techniques was to evaluate the corrosion control by using inhibitors.

Weight loss and Electrochemical measurements All the weight loss tests were obtained in a glass cell with coupons, which were removed every certain period of time; the time exposition total was 336 hours. Electrical Resistance probes were obtained by CORRDATA ${ }^{\circledR}$ Corrosion Monitoring System. Electrochemical techniques employed included, Linear Polarization Resistance, LPR, and Harmonic Distortion Analysis (HDA), which were obtained by using a SmartCET ${ }^{\mathrm{TM}}$ System. Linear Polarization Resistance and Harmonic Analysis were conducted with three electrodes mode. Linear Polarization Resistance technique involves measurements of the polarization resistance of a corroding electrode using a small amplitude polarization of the electrodes. The slope of the response at the corrosion potential, the polarization response, is then inversely proportional to the corrosion current. Harmonic Analysis technique is a measurement of the non-linear current distortion arising during the LPR measurement. The data is analyzed with the using Fast Fourier Transform analysis to provide a measure of the corrosion current, and to provide an on-line estimate of the corrosion rate calculation about the Stern-Geary constant.
Among the used inhibitors, commercial hidroxietilimidazoline type inhibitors were added at a $25 \mathrm{ppm}$ concentration which was found to be an optimum one to inhibit the corrosion phenomenon [7, 8, 9, 10]. Similar to the weight loss experiments, the working electrode was allowed to pre-corrode during 2 hours before the corrosion inhibitor was added. The inhibitors used were: HEIO, HEIE and HEIC. HEIO is an inhibitor whose chemical name is $1 \mathrm{H}$-imidazole-1-ethanol, 4,5-dihydro,-2-C15-17 unsaturated alkyl derivatives, the inhibitor HEIE is an inhibitor whose chemical name is $1 \mathrm{H}$-imidazole1-ethanol, 4,5-dihydro, -2-nor coco alkyl derivatives and HEIC is an inhibitor whose chemical name is 1H-imidazole-1-ethanol, 2-Heptadecyl-4, 5-Dihydro.

\section{RESULTS}

\section{Coupons Weight loss}

The corrosion rate by coupons weight loss was calculated through the equation (1):

$$
C R=\frac{K * W}{A * T * D}
$$

Where $\mathrm{CR}$ is the corrosion rate (mpy), $\mathrm{K}$ is a constant $\left(3.45^{*} 10^{6}\right), \mathrm{W}$ is weight loss during exposition time $(\mathrm{g})$, $\mathrm{A}$ is exposure area $\left(\mathrm{cm}^{2}\right)$, $\mathrm{T}$ is the exposition time (hours) and D is the density $\left(\mathrm{g} / \mathrm{cm}^{3}\right)$.

Table 1. Weight loss tests results.

\begin{tabular}{|c|c|c|c|c|}
\cline { 2 - 5 } \multicolumn{1}{c|}{} & \multicolumn{2}{c|}{$\begin{array}{c}3 \% \mathrm{NaCl} \\
\text { solution }\end{array}$} & \multicolumn{2}{c|}{$\begin{array}{c}3 \% \mathrm{NaCl}+ \\
10 \text { vol.\% diesel }\end{array}$} \\
\hline Inhibitor & $\begin{array}{c}\text { Corrosion } \\
\text { rate } \\
(\mathrm{mpy})\end{array}$ & $\begin{array}{c}\text { Inhibitor } \\
\text { efficiency } \\
(\%)\end{array}$ & $\begin{array}{c}\text { Corrosion } \\
\text { Rate } \\
(\mathrm{mpy})\end{array}$ & $\begin{array}{c}\text { Inhibitor } \\
\text { efficiency } \\
(\%)\end{array}$ \\
\hline- & 57.0 & - & 54.9 & - \\
\hline HEIO & 1.44 & 97.47 & 0.951 & 98.27 \\
\hline HEIE & 0.41 & 99.28 & 0.399 & 99.27 \\
\hline HEIC & 1.43 & 97.49 & 0.978 & 98.22 \\
\hline
\end{tabular}

Table 1 summarizes the weight loss results after exposing 1018 carbon steel during 336 hours to a $\mathrm{CO}_{2}$-saturated $3 \% \mathrm{NaCl}$ solution with and without $10 \mathrm{vol} . \%$ diesel at $50^{\circ} \mathrm{C}$ with and without 25 ppmof hidroxyethyl-imidazoline. The high efficiency of these inhibitors is evident, since the corrosion rate is decreased from 57 mpy for the uninhibited 3\% $\mathrm{NaCl}$ solution to 1.44 mpy, 0.41 mpy and 1.43 mpy 
respectively, obtaining an efficiency value of $97,47 \%$, $99.28 \%$ and $97.49 \%$ for each one of the inhibitors respectively. The corrosion products morphology of specimen in the uninhibited solution after 192 and 336 hours of exposure, consists of a porous layer of $\mathrm{FeCO}_{3}$, Figures 1-2, mainly siderite with equiaxial grains between 10-15 $\mu \mathrm{m}$ long.

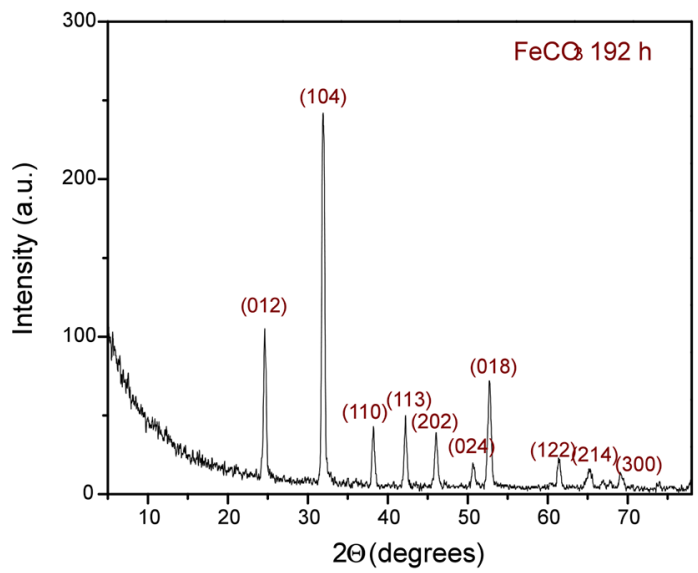

Figure 1. XRD patterns of the carbon steel coupons covered by $\mathrm{FeCO}_{3}$ in the uninhibited $\mathrm{CO}_{2}$-saturated $3 \% \mathrm{NaCl}$ solution at $50^{\circ}$. All peaks can be attributed to siderite).

\section{Electrical resistance (ER)}

Corrosion rate was calculated by the electrical resistance method too. The electrical resistance of a metal or alloy element is given through the equation (2):

$$
R=\frac{r * L}{A}
$$

Where $L$ is the probe element length $(\mathrm{cm}), A$ is the cross-sectional area $\left(\mathrm{cm}^{2}\right)$, and $r$ is the specific resistance of the probe metal $(\Omega * \mathrm{~cm})$. Reduction or metal loss in the element cross section, A, due to corrosion will be accompanied by an increase in the element electrical resistance $(R)$. To obtain the corrosion rate, a series of measurements are made over a period of time, and the results are plotted as a function of exposure time. The corrosion rate can be determined from the slope of the resulting plot $[5,6]$.

The results from the Electrical Resistance curves for 1018 carbon steel exposed to the $\mathrm{CO}_{2}$-saturated 3\%

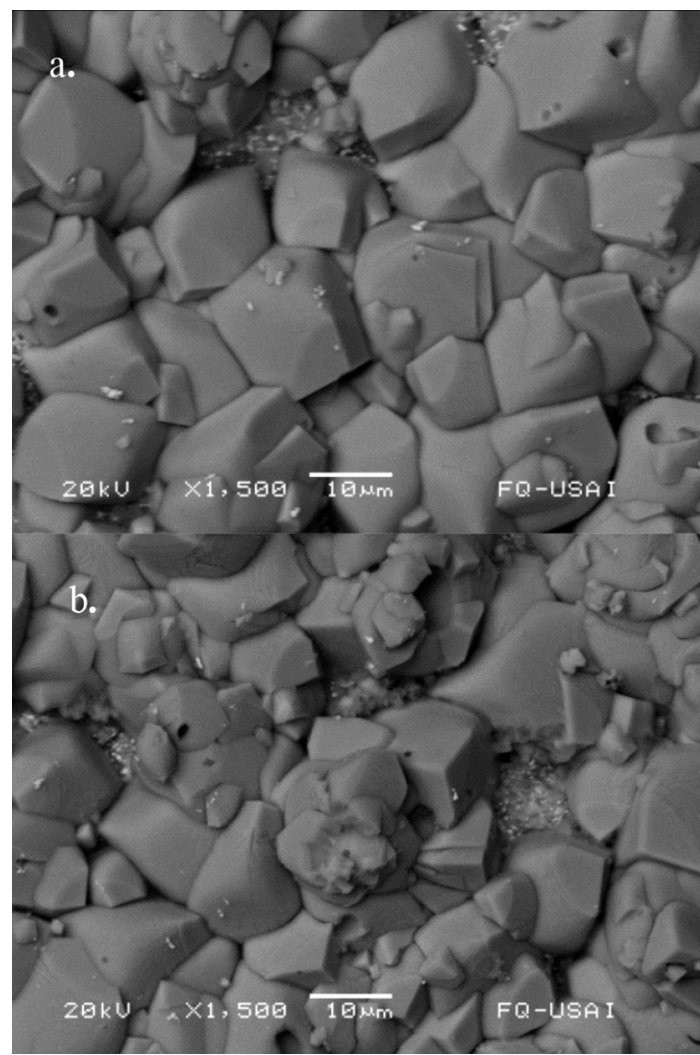

Figure 2. SEM micrograph of steel covered by FeCO after a) $192 \mathrm{~h}$ and b) $336 \mathrm{~h}$ of exposure to uninhibited $\mathrm{CO}_{2}$-saturated $3 \% \mathrm{NaCl}$ solution at $50^{\circ} \mathrm{C}$.

$\mathrm{NaCl}$ solution at $50^{\circ} \mathrm{C}$ with and without 25 ppmof inhibitors are shown on Figure 3. In this system the average corrosion rate value for the uninhibited solution was $72.6 \mathrm{mpy}$, with inhibitor addition the average corrosion rate, and after the inhibitors addition the corrosion rates were $0.65 \mathrm{mpy}$ inhibitor, $0.3 \mathrm{mpy}$ and 1.24 mpy for HEIO, HEIE and HEIC inhibitors respectively. With this technique, the higher efficiency of corrosion inhibitors were clear, obtaining efficiencies values of $98.95,99.61$ and $98.39 \%$ for HEIO, HEIC and HEIE inhibitors respectively.

The electrical resistance curves for 1018 carbon steel exposed to the $\mathrm{CO}_{2}$-saturated in mixture of $3 \% \mathrm{NaCl}+10$ vol. $\%$ diesel at $50{ }^{\circ} \mathrm{C}$ with and without hidroxyethyl imidazoline-type inhibitors are shown on Figure 4. The average corrosion rate value in the uninhibited solution was $77.3 \mathrm{mpy}$, but once the inhibitor was added the average corrosion rate was decreased down to 0.7 mpy with HEIO, 


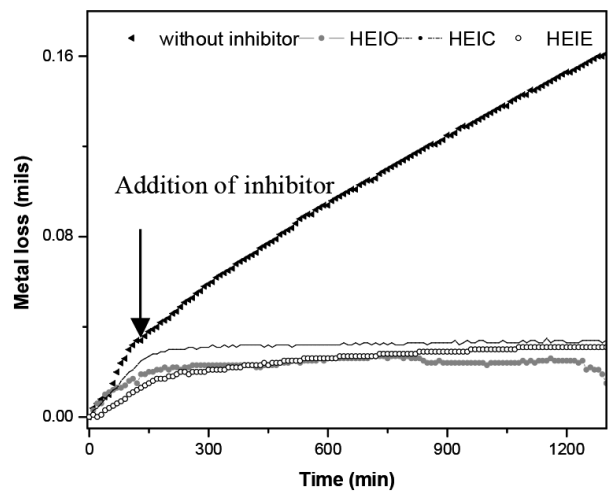

Figure 3. Metal loss data for Electrical Resistance probes with and without corrosion inhibitors type imidazoline in $\mathrm{CO}_{2}-$ saturated $3 \% \mathrm{NaCl}$ solution.

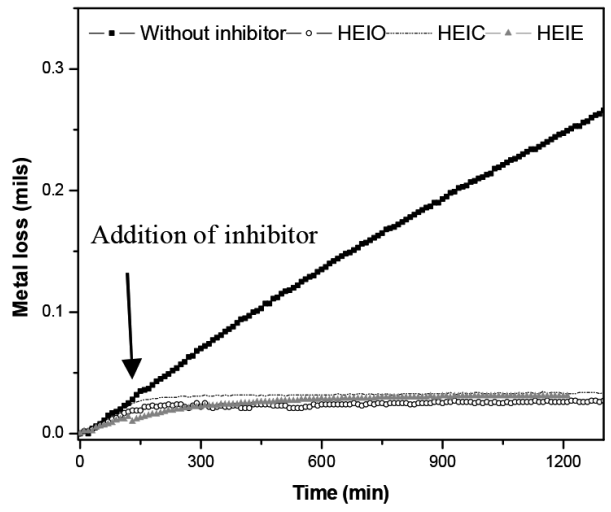

Figure 4. Metal loss data for Electrical Resistance probes with and without corrosion inhibitors type imidazolines in $\mathrm{CO}_{2}$-saturated $3 \%$ $\mathrm{NaCl}+10$ vol.\% diesel solution.

0.3 mpy with HEIE and 1.5 mpy for HEIC-type inhibitor. Similar to the obtained results in $3 \%$ $\mathrm{NaCl}$ without diesel, solution, the higher efficiency of these corrosion inhibitors were clear, obtaining efficiencies values of $99.07 \%$ for HEIO, $99.62 \%$ fory HEIE and $98.02 \%$ by HEIC-type inhibitor.

The industrial use of ER monitoring has been documented for various authors, G.R. Cameron and L.G. Coker [11] showed that sulfide environments present difficulties for the ER technique; electrically conducting iron sulfide corrosion products cause underestimates of metal loss. Gareau [12] illustrated the use of a computerized system for data transmission from several remote sites to a central control facility.
At this central facility, the ER data were monitored in real time, manipulated, and analyzed to obtain information on corrosion at the remote sites Thierry, Thoren and Leygraf, [13] compared the weight-loss results, ER measurements, and LPR measurements in cooling water systems. They concluded that the ER measurements indicated corrosion rates greater than those observed on the coupons when there was significant localized corrosion of the coupons, concluding that ER technique is sensitive to pitting attack and provides a rate that is some intermediate value between the general corrosion rate and the penetration rate.

\section{Electrochemical techniques}

The electrochemical nature of corrosion, allows that measurements of the electrical properties of the metal solution interface. In linear polarization resistance technique, a small potential perturbation is applied to the working electrode and the resulting current is measured. The ratio between the potential and current perturbations is known as the polarization resistance ( $\mathrm{Rp})$. That can be it related to the corrosion current through following Stern-Geary equation (3):

$$
R p=\frac{B}{i_{\text {corr }}}=\frac{\Delta E}{\Delta i}, \Delta E \rightarrow 0
$$

Where $R_{p}$ is the polarization resistance; $i_{\text {corr }}$ is the uniform corrosion current density and $B$ is an empirical polarization resistance constant that is related to the anodic ( $b a)$ and cathodic $(b c)$ Taffel slopes through the equation (4);

$$
\beta=\frac{b_{a} b_{c}}{2.3\left(b_{a} b_{c}\right)}
$$

The corrosion rate obtained by $r$ by linear polarization resistance are for 1018 carbon steel exposed to the $\mathrm{CO}_{2}$-saturated $3 \% \mathrm{NaCl}$ solution at $50^{\circ} \mathrm{C}$ with and without 25 ppminhibitor is shown in Figure 5, where it can be seen that the average corrosion rate without inhibitors was $150.87 \mathrm{mpy}$, but once the corrosion inhibitor was added the corrosion rate obtained were $0.81,0.14$ and 1.89 mpy for HEIO, HEIE and HEIC inhibitors respectively.

The corrosion rate obtained by linear polarization resistance are for 1018 carbon steel in the system with $\mathrm{CO}_{2}$-saturated $3 \% \mathrm{NaCl}+10$ vol. $\%$ diesel at $50{ }^{\circ} \mathrm{C}$, is shown in Figure 6, obtaining an average 


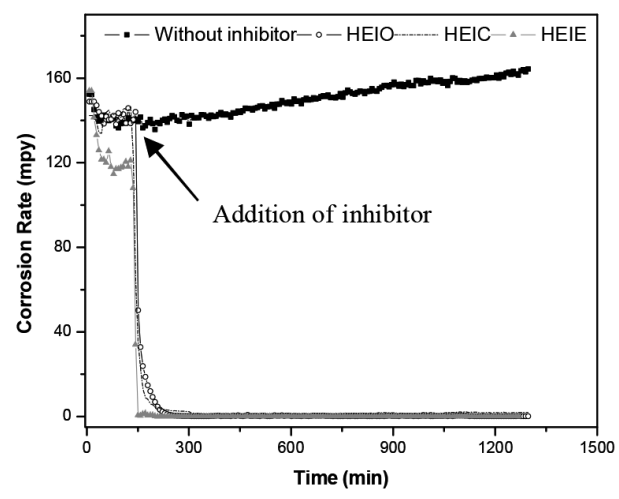

Figure 5. Corrosion rate obtained by LPR with and without corrosion inhibitors type imidazolines in $\mathrm{CO}_{2}$-saturated $3 \% \mathrm{NaCl}$ solution.

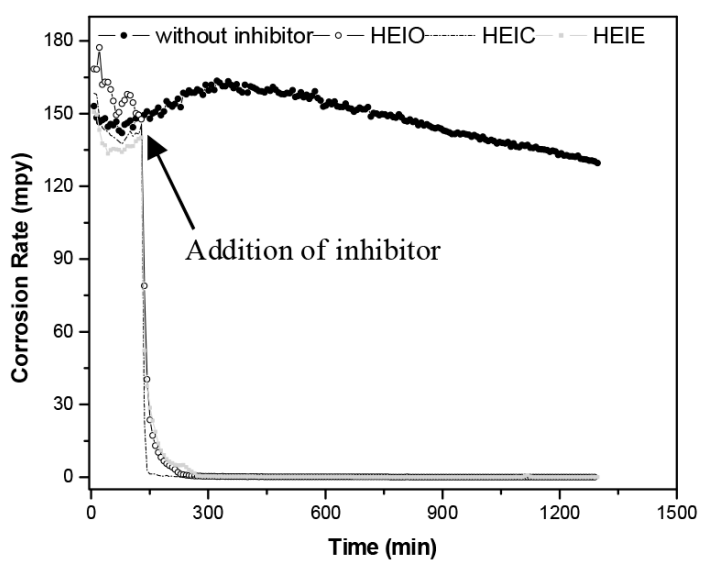

Figure 6. Corrosion rate obtained by LPR with and without corrosion inhibitor type imidazolines in $\mathrm{CO}_{2}$-saturated $3 \% \mathrm{NaCl}$ +10 vol. $\%$ diesel solution

corrosion rate without inhibitor of $144.47 \mathrm{mpy}$, whereas the average corrosion rates were 0.04 0.062 and 0.16 mpy for HEIO, HEIE and HEICtype inhibitors. It can be seen that in presence of diesel, the corrosion rates with inhibitors were much lower than those in absence of it, and, in all systems, the efficiency of inhibitor was evident, obtaining efficiency values higher than $99 \%$. It should be noted that all tests were performed by triplicated. Arrow indicated addition of inhibitor of corrosion and your effect immediately.

In the Harmonic Distortion Analysis technique, a low frequency sinusoidal potential is applied to a three electrode measurement system, and the resulting current is measured three different frequencies is used to verify the repeatability of the technique. The amplitude is in the range of $10-30-\mathrm{mV}$ peak to peak. The frequency used is typically $0.1-10 \mathrm{~Hz}$. Analyzing the primary frequency and the harmonics allow extraction of the required kinetic parameters of the corrosion process. Based on Stern-Geary model of the electrical double layer, a polarized electrode near the corrosion potential by a sinusoidal voltage of angular frequency $\omega$ and voltage amplitude Uo, over a period of time; $t$, gives a faradaic current density I $[6,14,15]$, given through the equation (5);

$$
i=i_{c o r r}\left(e^{2.3 u_{o} \sin _{b_{a}}^{w t}}-e^{2.3 u_{o} \sin _{b_{c}}^{w t}}\right)
$$

The current density of the Faradaic process will have a distorted sinusoidal form due to the non linear nature of the anodic and cathodic partial processes and will include higher harmonics having $\mathrm{k} \omega$ angular frequency $(\mathrm{k}=2,3, \ldots)$. This phenomenon is termed Faradaic distortion $[14,15,16,17,18$, 19]. The amplitudes of the harmonic components are obtained by Fourier's series expansion of the exponential terms, equation (6):

$$
i_{f}=i_{o}+i_{1} \sin w t-i_{2} \cos w t-i_{3} \sin w t+\cdots
$$

The first term of the series is the $i_{0}$ D.C component (Faradaic rectification), the coefficients of the other terms are the amplitudes of the harmonic components. For the first three harmonics components are given by equations (7), (8), and (9):

$$
\begin{aligned}
& i_{1}=2 i_{\text {corr }}\left[I_{1}\left(\frac{U o}{\beta_{a}}\right)+I_{1}\left(\frac{U o}{\beta_{c}}\right)\right] \\
& i_{2}=2 i_{\text {corr }}\left[I_{2}\left(\frac{U o}{\beta_{a}}\right)-I_{2}\left(\frac{U o}{\beta_{c}}\right)\right] \\
& i_{3}=2 i_{\text {corr }}\left[I_{3}\left(\frac{U o}{\beta_{a}}\right)+I_{3}\left(\frac{U o}{\beta_{c}}\right)\right]
\end{aligned}
$$

Where $\beta_{\mathrm{a}}=\mathrm{b}_{\mathrm{a}} / 2.303, \beta_{\mathrm{c}}=\mathrm{b}_{\mathrm{c}} / 2.303$, the first order modified Bessel functions are noted by $\mathrm{I}_{\mathrm{n}}(\mathrm{n}=1,2$, 3...). This formula can be simplified if Uo amplitude is limited to the extent $\left(\mathrm{Uo}<\beta_{\mathrm{a} \text { and }}\right.$ Uo $\left.<\beta_{\mathrm{c}}\right)$ that the Besel functions could be approximated with the small arguments. Thus, the equations derivate of above formula where simplified by Devay and Mészáros as follows by equations $(10,11,12)$ : 


$$
\begin{gathered}
i_{1}=i_{\text {corr }}\left(\frac{1}{\beta_{a}}+\frac{1}{\beta_{c}}\right) U_{o} \\
i_{2}=-i_{\text {corr }}\left(\frac{1}{\beta_{a}^{2}}-\frac{1}{\beta_{c}^{2}}\right) \frac{U_{o}^{2}}{4} \\
i_{3}=-i_{\text {corr }}\left(\frac{1}{\beta_{a}^{3}}-\frac{1}{\beta_{c}^{3}}\right) \frac{U_{o}^{3}}{24}
\end{gathered}
$$

Solving the equations system, Knowing amplitudes $i_{1}, i_{2}$, and $i_{3}$, Devay and Mészáros proposed the following equations for the determination of corrosion current for the determination of $i_{\text {corr }}, \beta_{a}$ and $\beta_{c \text {. }}$ equations $(17,18,19)$

$$
\begin{gathered}
i_{\text {corr }}=\frac{i_{1}^{2}}{\sqrt{48} \sqrt{2 i_{1} i_{3}-i_{2}^{2}}} \\
\frac{1}{b_{a, c}}=\frac{1}{4.6 U_{o}}\left(\frac{i_{1}}{i_{\text {corr }}} \pm 4 \frac{i_{2}}{i_{1}}\right)
\end{gathered}
$$

Figures 7 and 8 show the corrosion rate obtained by using the harmonic distortion analysis. In Figure 7, the average corrosion rate without inhibitor was $53.21 \mathrm{mpy}$, but once the corrosion inhibitors were added the average corrosion rate obtained were $0.78,0.29$ and 0.86 mpy for HEIE, HEIO and HEIC-type inhibitors respectively. Figure 8 shows that, when diesel is added, the average corrosion rate without inhibitor was $54 \mathrm{mpy}$, whereas with inhibitor the average corrosion rates were 0.42 , 0.088 and 0.46 mpy for HEIO, HEIE and HEICtype inhibitors respectively. Once again, with or without inhibitors, the corrosion rates in presence of diesel were lower than those obtained without diesel, and in all systems, the inhibitor efficiency was more than $99 \%$.

The corrosion rate obtained by using the LPR method in the uninhibited solution overestimates corrosion rates as compared to the results obtained by harmonic distortion analysis, but similar results were obtained by Durnie, Jefferson, and Kinsella [16] They demonstrated that Harmonic Distortion Analysis yields comparable corrosion rate data to LPR under a variety of carbon dioxide corrosion conditions, but a regular error of approximately $100 \%$ was evident in comparison to the HAD corrosion rates against comparable data obtained by using Linear Polarization Resistance, which was attributed to the assumed Tafel slopes in the LPR,

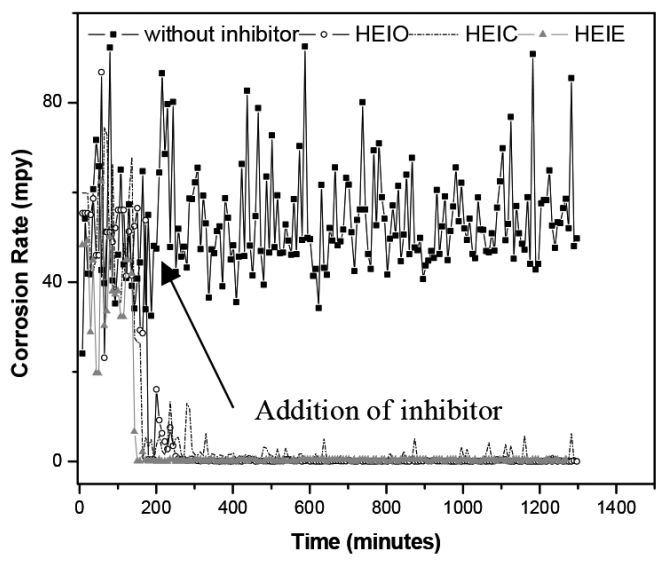

Figure 7. Corrosion rate measured by Harmonic Distortion Analysis with and without corrosion inhibitor type imidazolines in $\mathrm{CO}_{2}$-saturated 3\% $\mathrm{NaCl}$.

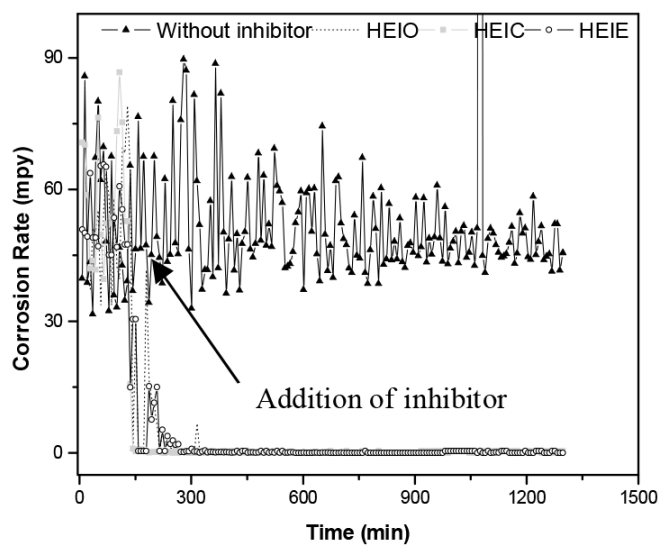

Figure 8. Corrosion rate measured by Harmonic Distortion Analysis with and without corrosion inhibitor type imidazolines in $3 \% \mathrm{NaCl}+10$ vol. $\%$ diesel.

while HAD is capable of determined Tafel Slopes in each measurement cycle.

Thus, it can be concluded from all the obtained results with the different techniques, the differences in the obtained results with the SmartCET equipment id sue to the fact that this is a "Black box" which does not allow us to know the used scan rate, Tafel slopes, etc. It can be said that by using these equipments the use of corrosion inhibitors can be monitored to detect its action on the metal surface and their persistency on top of the metal surface. 
Finally, some polarization curves were performed for 1018 carbon steel exposed to the $\mathrm{CO}_{2}$-saturated 3\% $\mathrm{NaCl}$ solution and $\mathrm{CO} 2$ saturated 3\% NaCl-Diesel at $50^{\circ} \mathrm{C}$ with and without 25 ppmof hydroxyl ethyl type imidazolines are shown on Figures 9 and 10.

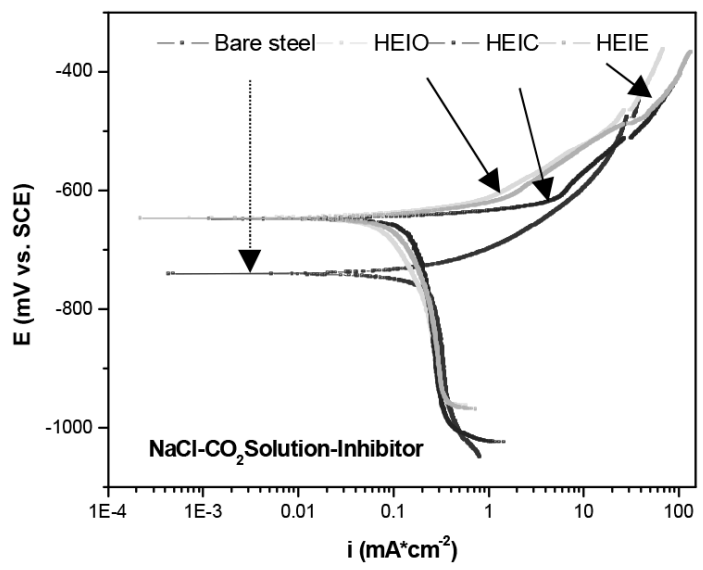

Figure 9. Effect of $25 \mathrm{ppm}$ corrosion inhibitor type imidazolines on the polarization curves for carbon steel in a $\mathrm{CO}_{2}$-saturated $3 \%$ $\mathrm{NaCl}$ solution at $50{ }^{\circ} \mathrm{C}$.

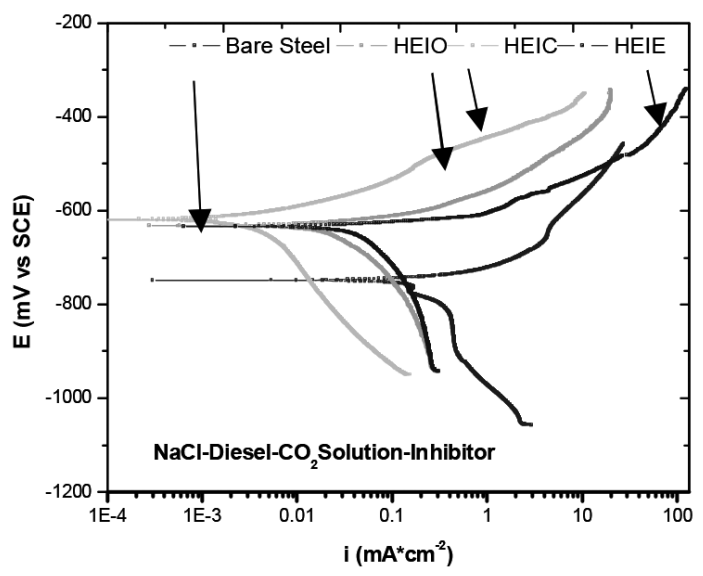

Figure 10.Effect of $25 \mathrm{ppm}$ corrosion inhibitor type imidazolines on the polarization curves for carbon steel in a $\mathrm{CO}_{2}$-saturated $3 \% \mathrm{NaCl}$ solution-Diesel at $50{ }^{\circ} \mathrm{C}$.

In the solution without diesel, Figure 9, it can be seen that in both cases the data describes a distinctly active behavior, without demonstrating the existence of a passive layer. The $\mathrm{E}_{\text {corr }}$ value for the uninhibited solution was $-740 \mathrm{mV}$, which was nobler than for the inhibited solution $(-640 \mathrm{mV})[20,21]$. For the uninhibited solution, the existence of a cathodic limiting current density value can be seen, give carbonic acid as follows (1):

$$
\mathrm{CO}_{2}+\mathrm{H}_{2} \mathrm{O} \rightarrow \mathrm{H}_{2} \mathrm{CO}_{3}
$$

Subsequently that the solution is de-aerated, the dominant cathodic reactions are the reduction of $\mathrm{H}^{+}$ions, dissociation of carbonic acid $(2,3,4)$ :

$$
\begin{gathered}
\mathrm{H}_{2} \mathrm{CO}_{3}+e^{-} \rightarrow \mathrm{H}^{+}+\mathrm{HCO}_{3}^{-} \\
\mathrm{HCO}_{3}^{-}+e^{-} \rightarrow \mathrm{H}^{+}+\mathrm{CO}_{3}^{2-} \\
2 \mathrm{H}^{+}+2 e^{-} \rightarrow \mathrm{H}_{2}
\end{gathered}
$$

And water reduction as follows (5):

$$
2 \mathrm{H}_{2} \mathrm{O}+2 e^{-} \rightarrow 2 \mathrm{OH}^{-}+\mathrm{H}_{2}
$$

The main anodic reaction, in absence of inhibitor, is iron dissolution according to (6):

$$
\mathrm{Fe} \rightarrow \mathrm{Fe}^{2+}+2 e^{-}
$$

Though it may be through several steps. During this corrosion process, a corrosion scale of iron carbonate, $\mathrm{FeCO}_{3}$, would form on the surface of carbon steels according to (7):

$$
\mathrm{Fe}^{2+}+\mathrm{CO}_{3}^{-2} \rightarrow \mathrm{FeCO}_{3}
$$

In absence of oxygen, the primary cathodic reactions are dependent on the $\mathrm{pH}$ solution, and it could be the reduction of bicarbonate ions, water and hydrogen ions, equations (3), (4) and (5). At a low $\mathrm{pH}$ value, $\mathrm{H}^{+}$reduction is the governing cathodic reaction because of the high $\mathrm{H}^{+}$concentration. When $\mathrm{pH}$ increases to $4-6$, as in the present case, the direct reduction of $\mathrm{HCO}_{3}{ }^{-}$and $\mathrm{H}_{2} \mathrm{CO}_{3}$ become important. At a high overpotential, the governing cathodic reaction changes to direct reduction of water. Thus, in the present case, the diffusion of $\mathrm{HCO}_{3}{ }^{-}$and $\mathrm{H}_{2} \mathrm{CO}_{3}$ ions to from iron carbonate, $\mathrm{FeCO}_{3}$, is the rate controlling step, which is independent of the inhibitor concentration, as shown in the cathodic branch of polarization curves in Figure 2. On top of this iron carbonate film, the inhibitor-formed film is insulating that protect the metal from the electrolyte. 
The change in the corrosion rate with time, obtained from the LPR results, is shown in Figure 6, where it can be seen that for the uninhibited solution, the corrosion rate remained constant with time. However, as soon as 25 ppmof corrosion inhibitor was added, the corrosion rate decreased for more than four orders of magnitude.

In presence of Diesel, Figure 10, the $\mathrm{E}_{\text {corr }}$ value for the uninhibited solution was $-740 \mathrm{mV}$, which was made noble for the inhibited solution and was $-610 \mathrm{mV}$ approximately. This shows the effect of the inhibitor, where the data exhibited that the $\mathrm{E}_{\text {corr }}$ was $-610 \mathrm{mV}$ approximately. This can be due to the fact that the inhibitor is soluble in diesel and dispersible in water, thus, a better transport o is expected, and, thus improve its corrosion performance.

\section{CONCLUSIONS}

Real time corrosion monitoring, both electric resistance or electrochemical as developed for the system pertaining the current investigation has proved to be a reliable tool to predict internal corrosion with an accuracy that is very similar to that measured employing internal corrosion coupons, with the enormous advantage of enabling the pipeline operator to react with due anticipation and reactive capacities. The one-month lapse where all corrosion damage inside a pipeline, and therefore in a coupon is "averaged" as a time uniform metal loss. Real time corrosion monitoring may be useful to detect immediately a change in corrosivity due to a process distortion, such as a sudden change in the water content in the pipeline; the input of a mixture of fluids with highly corrosive agents; or in the best situation to communicate the operator that the pipeline is working steadily.

The remarkably good correlation among Electrical Resistance, Harmonic Distortion Analysis corrosivity results, and that averaged as weight loss coupons in corrosion system is apparent when the system was studied without corrosion inhibitors. The Harmonic Distortion Analysis technique present an advantage respect to Linear Polarization Resistance due the simultaneous production of Tafel slopes, eliminating the approximation imposed by using assumed Tafel slope values in Linear Polarization Resistance. The real time monitoring techniques such as Electrical Resistance, Linear Polarization
Resistance and Harmonic Distortion Analysis represent a fundamental breakthrough, since they offer the possibility of measuring changes in corrosion rate rapidly and accurately. This approach was successfully validated in a corrosive system with $\mathrm{CO}_{2}$-saturated in $3 \% \mathrm{NaCl}$ solution and mixture of $90 \mathrm{vol} . \%$ of $3 \% \mathrm{NaCl}$ and 10 vol. $\%$ diesel at $50{ }^{\circ} \mathrm{C}$, both with and without the participation of corrosion inhibitors.

\section{ACKNOWLEDGEMENTS}

Andrea Cáceres would like to acknowledge to Consejo Nacional de Ciencia y Tecnología (CONACYT, México) by Ph. D. graduate by scholarship.

The authors would like to acknowledge to Q. Ivan Puente, Facultad de Química-UNAM, for their technical support in scanning electron microscopy and would like to acknowledge to M. L. Ramon Garcia, CIE-UNAM for their technical support in Diffraction ray-X and P. Altuzar-Coello, CIE-UNAM.

\section{REFERENCES}

[1] P.R. Roberge. "Corrosion Inspection and Monitoring". John Wiley \& Sons Inc., Publication. 1 Edition, pp. 189-199. Ontario, Canada. Online ISBN: 9780470099766. 2007.

[2] A. Abdulhadi, M.F. Al-Subaie, A.M. Al-Zahrani, M.M. Al-Qarni. "Field and Laboratory Experiences with Advanced Electrical Resistance Online Corrosion Monitoring System”. Paper No 07265. NACE International. Nashville, EE.UU. 1 January 2007.

[3] D.C. Eden and D.A. Eden. "On-line, real-time optimization of corrosion inhibitors in the field", Paper No. 06321. NACE international. San Diego, EE.UU. 12-16 March 2006.

[4] A.J. Freedman, E.S. Troscinski, A. Dravnieks, "An Electrical Resistance Method of Corrosion Monitoring in Refinery Equipment". CORROSION. Vol. 14. Issue 4, pp. 29-32. 1958. https://doi.org/10.5006/0010-9312-14.4.29

[5] Standard Guide for Online Monitoring of Corrosion in Plants Equipment. Annual Book of American Society for Testing of Materials, G 96-90. Philadelphia, EE.UU. 2001. 
[6] J. Dévay and L. Mészáros. "Study of the Rate of Corrosion of Metals by Faradaic Distortion Method". Acta Chimica Academiae. Scientarium Hungaricae, Tomus 100, 1-4, pp. 183-202. 1979. ISSN 0231-3146

[7] J. Cruz, R. Martínez, J. Genescá and E. García Ochoa. "Experimental and theoretical study of 1-(2-ethylamino)-2-methylimidazoline as an inhibitor of carbon steel corrosion in acid media". Journal of Electroanalytical Chemistry, Vol. 566, pp. 111-121. 2003. DOI:10.1016/j.jelechem.2003.11.018

[8] W. Villamizar, M. Casales, J.G. GonzalezRodriguez and L. Martinez. " $\mathrm{CO}_{2}$ corrosion inhibition by hydroxyethyl, aminoethyl, and amidoethyl imidazolines in wateroil mixtures". Journal of Solid State Electrochemestry, Vol. 11 No 5, pp. 619-629. 2007. DOI 10.1007/s10008-006-0208-x

[9] S.T. Keera, N.A. Farid and K.Z. Mohamed. "Imidazoline Derivatives as Corrosion Inhibitors of Carbon Steel in Crude Oils and Associated Water". Energy Sources, Part A: Recovery, Utilization, and Environmental Effects. Vol. 34, Issue 15, pp. 1371-1383. 2012. DOI: $10.1080 / 15567036.2010 .481657$

[10] B.Wang,M.Du, J.Zhang, C.J.Gao. Electrochemical and surface analysis studies on corrosion inhibition of Q235 steel by imidazoline derivative against $\mathrm{CO}_{2}$ corrosion". Corrosion Science. Vol. 53, Issue 1, pp. 353-361. 2011. https://doi. org/10.1016/j.corsci.2010.09.042

[11] G.R. Cameron and L.G. Coker, "Oil Production Corrosion Inhibitor Optimization by Laboratory and Field Application of Electrochemical Techniques". ASTM STP 908, pp. 251-265. 1986. DOI: 10.1520/ STP17450S

[12] F.S. Gareau. "Remote Corrosion Monitoring Using an Interactive Data Acquisition and Transfer System". Paper 107, Corrosion 88, NACE Publication, Houston, EE.UU. 1988.

[13] D. Thierry, A. Thoren and C. Leygraf. "Corrosion Monitoring Techniques Applied to Cooling Water and District Heating
Systems". Paper 463, Corrosion 87, NACE Publication, Houston, EE.UU. 1987.

[14] G.L. Cooper. "Sensing Probes and Instruments for Electrochemical and Electrical Resistance Corrosion Monitoring". ASTM STP 908, pp. 237-250. 1986. DOI: 10.1520/STP17449S

[15] A. Pirnát, L. Mészáros and B. Lengyel. "A comparison of electrochemical and analytical chemical methods for the determination of the corrosion rate with very efficient inhibitors". Corrosion Science. Vol. 37, Issue 6, pp. 963-973. 1995. https://doi. org/10.1016/0010-938X(95)00007-7

[16] W. Durnie, T. De Marco, A. Jefferson, B. Kinsella. "Harmonic Analysis of Carbon Dioxide corrosion". Corrosion Science. Vol. 44, Issue 6, pp. 1213-1221. 2002. https:// doi.org/10.1016/S0010-938X(01)00136-6

[17] S. Sathiyanarayanan and K. Balakrishnan. "Critique of harmonic analysis for corrosion rate measurements". British Corrosion Journal. Vol. 29 No 2, pp. 152-155. 1994. DOI: $10.1179 / 000705994798267827$

[18] J.P. Diard, G. Le Gorrec, C. Montella, "Application of Harmonic Analysis in the Measuring Technique of Corrosion". Journal Electrochemical. Society. Vol. $142 \mathrm{~N}^{\circ} 10$, pp. 3612. 1995. DOI:10.1149/1.2148758

[19] A. Castañeda Valdés, C. Valdés Clemente y F. Corvo Pérez. "Uso de la técnica de armónicos de corriente alterna en el estudio y comparación de la corrosión en el acero de refuerzo". Revista CENIC Ciencias Químicas. Vol. $41 \mathrm{~N}^{\circ} 2$, pp. 113-121. 2010. ISSN: 1015-8553 ISSN electrónico: 2221-2442.

[20] S.K. Rangajaran. "Random processes in electrochemistry: Part I. Noise as an input signa". Journal of Electroanalytical Chemistry. Vol. 62 Issue 1, pp. 43-50. 1975. https://doi. org/10.1016/0022-0728(75)80026-X

[21] D.M. Ortega-Sotelo, J.G. González Rodriguez, M.A. Neri Flores, M. Casales \& L. Martínez, A. Martínez Villafañe. "CO2 corrosion inhibition of X-70 pipeline Steel by carboxyamido imidazoline". J Solid State Electrochem. Vol. 15, pp 1997-2004. 2011. DOI: $10.1007 / \mathrm{s} 10008-010-1226-2$ 